\title{
Offshoring Professional Services: Institutions and Professional CONTROL
}

Kyoung-Hee Yu, Australian School of Business, University of New South Wales ${ }^{1}$

Frank Levy, Massachusetts Institute of Technology

\section{INTRODUCTION}

Globalization is frequently described as having integrated national markets into one single market. In a review of the 90s literature, Berger (2000) points out that "there is a common understanding of globalization as a set of changes in the international economy that tend to produce a single world market for goods, services, capital and labor” (44). Ohmae (1999) goes further to say that "interlinked economies" have wiped out national borders. With respect to work, globalization has been associated with the movement of capital, and the corresponding movement of jobs. Research on production value chains suggests that work can now go anywhere seeking the right skills, the right price, and the right context (Gereffi, 2003; Gereffi \& Kaplinsky, 2001; Sturgeon \& Lester, 2002).

Most examples leading to these conclusions, however, come from manufacturing and back office services. In a 1998 survey of the state of manufacturing around the world, the Economist stated that one saw an "emergence of a global structure for manufacturing” (18) with prototypical examples in textiles and electronics. The firm-level strategy was exemplified by Asian firms, using their capital and manufacturing knowhow to invest in Mexican maquiladora factories with cheaper labor in order to sell to the American market. Professional services were generally absent in these enduring descriptions of globalized production.

In 2005, however, a New York Times article and articles in physician trade journals announced that globalization had reached diagnostic radiology, a highly skilled professional service that in the U.S. requires a bachelors degree and seven years of post baccalaureate medical education.

\footnotetext{
${ }^{1}$ Corresponding author. E-mail: khyu@unsw.edu.au; Mailing address: School of Organisation and Management, ASB Building L5, UNSW, Sydney, NSW 2052
} 
According to these articles, a large and growing number of U.S. medical images were being read by low wage radiologists in India. As we have shown elsewhere, these reports were highly exaggerated for the U.S. market. But focusing only on offshoring to India belies a more important distinction between diagnostic radiology and well-known practices in non professional work. In this paper we seek to address this distinction. We first provide a theory which explains why national institutions are more likely to influence offshoring of professional services than the offshoring of manufacturing or back office services. We then provide data on the variations in a specific case - the offshoring of diagnostic radiology in the U.S., U.K., and Singapore - to show how differences in national institutions continue to act upon market transactions of professional services even in a globalized world. All three countries are offshoring diagnostic radiological reads, but primarily for reasons other than cost. The U.S. offshores radiology work to U.S. board certified radiologists who are located abroad. The U.K. offshores radiology largely to radiologists trained in other EU countries. Only Singapore offshores any significant amount of this work to India.

\section{VARIATIONS IN OUTCOMES OF GLOBALIZATION - PROFESSIONAL VS NON PROFESSIONAL WORK}

Even as the force of globalization is described in sweeping terms, there has been growing awareness of the unevenness of change - across sectors, across industries, and across nations (Campbell, 2004; Hay \& Rosamond, 2002; Immergut, 1992; Streeck \& Thelen, 2005). Studies showed that globalization as a "non-negotiable external constraint” is more of a strategic rhetoric to advance unpopular socioeconomic reforms in formerly protected markets than it is a uniform reality (Hay et al., 2002). One explanation for why change is uneven across sectors is that change is often incremental and builds on what went before. Scholars studying institutional change suggest various mechanisms of gradual, rather than epistemic, institutional changes including “bricolage”, drift, conversion, and layering (Streeck et al., 2005). Gradual changes that build on features of old institutions can explain why national institutions continue to be relevant even in the face of expanding global markets. As John Campbell (2004) writes, "No one in their right mind would deny that change in national political economies has occurred of late. The question is how much and in which institutions.” (Campbell, 2007). 
Scholars have shown that countries, sectors, and industries are vulnerable to forces of market integration to different extents (Frieden, 1991; Hay et al., 2002). In previous literature, this variation has been attributed to differences in institutions (Hall \& Soskice, 2001); differential rates and patterns of institutional changes (Streeck et al., 2005); and the abilities of groups of actors to influence economic integration (Hay et al., 2002). But in this literature, there has been little focus on how globalization may impact professional work, where discretion and judgment are involved in the work performed and the work may be embedded in highly institutionalized fields.

In the case of professional work, two theoretical approaches suggest why global integration will be slower than it is for manufacturing or non-professional services. The first is an actor-centered explanation that hinges on professionals' superior power in controlling their work. Friedson's 1970 framework of professional dominance would predict that professions, because of their dominant (sometimes exclusive) position in the education, training, and practice of a particular occupation, would effectively safeguard their work by mobilizing institutional resources to oppose offshoring. In particular, Friedson theorized that a certain professions' control over their work would be sanctioned by the state, thus creating a monopoly over knowledge and resources:

The foundation on which the analysis of a profession must be based is its relationship to the ultimate source of power and authority in modern society - the state. In the case of medicine, much, though by no means all, of the profession's strength is based on legally supported monopoly over practice. This monopoly operates through a system of licensing that bears on the privilege to hospitalize patients and the right to prescribe drugs and order lab procedures that are otherwise virtually inaccessible. (Friedson 1971: 117)

Friedson showed how professional dominance acted in concert with other institutional arrangements - formal, such as regulatory systems ruling on certification, and informal, such as social relationships among physicians that reinforce their authority over patients and over diseases.

The second explanation is based on the structure of knowledge involved in professional work. Because professional work involves tacit knowledge, and because this knowledge is hard to 
measure, suppliers in other countries may find it hard to demonstrate quality, while buyers may deem it more risky to buy services from abroad (Levy \& Murnane, 2004). ${ }^{2}$

These two reasons help to explain why professional services may be harder to send offshore than manufacturing or back-office services, but they do not explain the variation in professional offshoring across countries. We believe this variation is best explained by a third aspect of professional services - the institutional environment in which professional services operates, particularly the potential for a strong government role. Drawing on concepts of institutionalist theory, we argue that national institutions determine how much professional work is offshored and how this process is governed in two ways. First, national institutions set regulations that govern offshoring practices directly. Second, national institutions determine the level of power professionals have in controlling their work. We find that changes in the recent decades in national healthcare systems, which in some cases were quite significant, do not affect this overall trend.

\section{Institutions AND Professional ConTrol}

The stickiness of national institutions in the face of forces of globalization has been traditionally explained in terms of path dependency, which emphasizes that institutions are self-reinforcing (Collier \& Collier, 1991). But path dependency explanations tend to obscure the fact that institutions are maintained through active participation from actors in favor of the status quo, or despite actors' efforts to thwart the current state. We draw on existing literatures on agency and professional control to argue that professionals are likely to seek to influence policies and rules affecting control over their work, but that the extent of their agency will be heavily dependent on the level of their autonomy vis-à-vis the state.

\footnotetext{
${ }^{2}$ Although we will draw comparisons with manufacturing and low-end service work, one should note that we do not depict these as wholly different worlds. The difference is one of degrees of political and institutional power rather than some pre-determined rule. Even in manufacturing, institutional arrangements made it hard for capital (and thus jobs) to be completely footloose. NAFTA, for example, acted as an effective barrier to Asian investors who relocated to Tijuana, Mexico, in order to sell to the U.S. market. Furthermore, factors such as knowledge of customer preferences and quickly changing market situations made location a more complicated decision than a simple race for the lowest cost of production.
} 
Actors' propensities to exercise agency has been described in institutionalist theory in terms of willingness on the one hand and capability to access resources on the other - whether material or normative (Lawrence, 1999). In these respects, professionals have been described to be well placed to influence institutions. Professions dominate the state of knowledge in their fields, and thus exercise considerable authority over educational institutions (Abbott, 1988). Second, professionals are guaranteed virtual monopoly over their field of practice via regulatory and certifying institutions that purvey this sovereignty (Freidson, 1970). Finally, professionals exert normative control over institutional standards and practices through socialization of new members into their occupational group (Scott, 2001). These accounts of professional power help explain why professionals may exercise more influence over institutions compared to other workers. However, professional power may also be challenged or constrained by the state. To understand how professional power may be curbed by government action, we need a more contextualized account of professional agency that defines it in terms of its position within the institutional milieu, particularly its relationship to the state.

Previous research in agency has argued that actors impact institutional change in two ways through rule-making activities on the one hand, and through legitimating activities on the other (Friedland \& Alford, 1991; Lawrence \& Suddaby, 2006; Suddaby \& Greenwood, 2005). Rulemaking activities appeal to formal authority, whereas legitimating activities appeal to deep underlying logics that theorize the desirability or legitimacy of a particular institution over another. We argue that both these activities are mediated by the structural position of actors within the institutional milieu and their relationship to the state. That is, we advocate both a more deeply embedded view of actors in their institutional terrain, as well as a more institutionalized view of action. In this more institutionalized view of agency, actors' abilities to influence institutions are not primarily a function of their social or political skills; instead, they are enabled or impeded by their position in the division of labor within the institutional configuration. This way of conceptualizing agency will allow us to understand not only when actors are able to contribute to changing or maintaining institutions (Lawrence et al., 2006), but also when such efforts fail to produce the intended results. 
For various reasons including, as we noted earlier, the ambiguous nature of determining quality in professional work, states will vary in their efforts to regulate the professional services. State intervention in professional services can take several forms, inter alia, the delineation of a public sector in which services are owned by the government (i.e. public healthcare); regulation of certification; the establishment of incentive structures for professionals; and the introduction of reforms to change various aspects of professional work. For medical professionals, state intervention can vary along a spectrum. At one end, the doctors are employees of a state that has its own agenda - societal equity concerns, political interests for re-election, national economic development, etc. At the other extreme, the state is captured by the doctors who use the state's authority to legitimize their own agenda of professional dominance.

\section{METHODS}

This project began with an investigation of strategies that Indian firms were taking to provide diagnostic radiologic reads to the U.S. market. We identified two Indian firms that were not only leading the effort to provide services to the U.S. but also were the only Indian entities that had had some success in doing so. The difficulties that these firms had experienced in penetrating the U.S. market, as well as these firms’ ongoing efforts to provide services to the U.K. and Singapore, led us to expand the project to examine the institutional make-up of healthcare and offshoring patterns in all three markets that the Indian firms were targeting.

We used existing research to map out the features of the institutional terrain in U.S., U.K. and Singapore. In addition, we conducted content analysis of media reports to trace the following for each country: recent changes in healthcare; the use of teleradiology to provide diagnostic reads; and the issue of offshoring radiologic reads. During the course of this research we have developed a network of informants comprising radiologists and researchers in all four countries whose communications with us, including formal telephone interviews and informal e-mail exchanges, provided important leads and at times, corrections to our own research. Fieldwork in India was conducted in two phases - the first a short visit to India by the first author in the summer of 2004, and the second a month-long field investigation by the first author in the summer of 2005. 


\section{The Profession of Diagnostic Radiology}

In his analysis of professional control, Friedson distinguished between what he called "colleague dependent” and “client dependent” occupations in the medical profession. He argued that colleague dependent occupations would be far more likely to exert control over individual practitioners through inter-collegial enforcement of standards and norms (1970:93). Friedson referred to radiology as a prime example of “colleague-dependent” medicine. We would add to this that within the field of radiology, diagnostic radiologists are more colleague-dependent than other radiology specialties since almost all of their work involves referrals from other doctors. ${ }^{3}$ Their work, including any errors, is highly visible to members of other specialties. Thus they are more open to peer influence over how they practice their work.

Since radiology is an integral part of a chain of diagnoses, radiologists have historically had little control over when they work. Particularly in emergency situations, they must interpret images as they arrive and return a diagnosis in a limited time frame. At the same time, the portability of $\mathrm{x}$ ray images mean radiologists have always had far greater control over where their work was done (Linton, 2001). Since the early 1980s, the portability of the radiologist's work has been hugely increased by the digitization of radiology images. Digitization permanently divorced the location where the scan is taken from the location of where a radiologist interprets an image (but as we will see later, location concerns did not disappear altogether). Whereas physical x-ray prints could be transported only short distances in a short time, digital images can be sent anywhere where the radiologist has internet access.

Changes in technology since the 1980s, such as the continued improvement in scanners, increased the volume of digitized scans that radiologists interpret, as well as their variety. To take two examples, the development of PET scanners allows a doctor to identify the level of body activity rather than just a cross-section snapshot. This makes PET scans very useful in identifying cancerous tumors with their very high levels of metabolic activity. Similarly, the

\footnotetext{
${ }^{3}$ For example, an interventional radiologist uses images for guidance as they perform such procedures as the insertion of a stent or a catheter. For obvious reasons, this work is not being offshored.
} 
current 64 slice generation of CT scanners can do detailed cardiac imaging while 32 slice and earlier CT scanners cannot.

We noted above that a key dimension of professional services is a reliance on tacit knowledge. In the case of radiology, one indication of this reliance is the slow progress of Computer Aided Diagnosis software - pattern recognition software that attempts to highlight possible abnormalities in an image. To be successful, this software requires an estimated set of statistical rules that underlie the radiologist's judgment. In most cases, estimating these rules has so far proven impossible and so the radiologist continues to rely on tacit skills that take significant time to teach. ${ }^{4}$ One result of prolonged education is that in all four countries that we studied, radiologists were relatively scarce in number compared to a high and growing demand for their skills. Presumably, the shortages are higher in countries where use of digitized technology in radiology is more widespread. But radiologists are also scarce in India, where the number of physicians per 1,000 people is one of the lowest in the world (World Health Organization). In many countries like the U.S., where the number of first-year medical school seats and residency seats are limited by federal regulation, government involvement in medical education has also restricted the supply of radiologists (Grumbach, 2002; Reinhardt, 1999). ${ }^{5}$

Lifestyle pressures on radiologists, and the impact of a shortage of radiologists on the delivery of medical diagnosis have led to a widening of the practice of teleradiology, the practice of reading scans and delivering reports remotely. Teleradiology has in turn led to increased outsourcing and the creation of new forms of organizations. Variable contractual arrangements have emerged in the countries of our study between on-site and off-site radiologists. In some cases, teleradiology has allowed radiologists to reorganize their own resources - for example, allowing a doctor on night call to read images from home rather than coming into a hospital. But the cases that are relevant for this paper involve hospitals contracting with outside teleradiology firms -

\footnotetext{
${ }^{4}$ In the United States, for example, the Food and Drug Administration has approved only two applications of Computer Aided Diagnosis software for reimbursement: one in mammograms and the other in lung scans. Both cases involves "simpler" problems where there is only one potential abnormality of interest.

${ }^{5}$ By accident, the Balanced Budget Act of 1997 limited federal funding for residency slots at the moment when radiology salaries were low and medical students were choosing other specialties. Since that time, the demand for radiologists has increased substantially but increasing the number of radiology slots today would mean getting other professions to give up their slots, something that is unlikely to happen.
} 
independent groups of radiologists that communicate their work through the internet. For a hospital with limited staff, a teleradiology firm can offer a way to quickly expand capacity. For a small hospital with limited nighttime activity, a teleradiology firm can handle the small number of nighttime emergency room images at lower cost than hiring a full nighttime radiologist or requiring the hospital's own radiologists to be on night call (Goelman \& Massachusetts Institute of Technology. Dept. of Urban Studies and Planning., 2005).

The U.S., U.K. and Singapore were actively experimenting with ways to use technology and work arrangements differently in order to deal with varying degrees of supply shortages. In all three countries, there are common pressures to outsource and offshore excess work. While we observe offshoring in all three countries, offshoring has taken distinct forms in each of these countries with important implications for professional control. The differences include regulatory constraints governing cross-border medical practice, organizational arrangements, and the range of destination countries, including particularly the possibility of offshoring work to a country with considerably lower labor costs, India. In the remainder of the paper we trace the healthcare system in each country and show how patterns in offshoring diagnostic radiology are contingent on the ability of the radiologists to influence the changing institutional environment. We then address specifically the problem of offshoring diagnostic radiology to India, a country that all three origin countries attempted to send scans to, but only one, Singapore, succeeded in doing so.

Table 1. Salary Levels of Diagnostic Radiologists in the Countries of Study

\begin{tabular}{|l|r|}
\hline Country & \multicolumn{1}{|l|}{ US dollars } \\
\hline India & 35,000 \\
\hline Singapore (private sector) & 95,000 \\
\hline United Kingdom (NHS) & 140,000 \\
\hline United States & 280,000 \\
\hline
\end{tabular}

Sources: interviews (UK, Singapore, India); www.salary.com (U.S.)

Table 2. Density of Physicians per 1,000 population, Selected Countries 


\begin{tabular}{|c|c|c|}
\hline Country & $\begin{array}{l}\text { Physicians per } \\
1,000\end{array}$ & $\begin{array}{l}\text { Latest Year data } \\
\text { available }\end{array}$ \\
\hline India & 0.60 & 2004 \\
\hline Chile & 1.09 & 2003 \\
\hline Singapore & 1.40 & 2001 \\
\hline United Kingdom & 2.30 & 1997 \\
\hline United States of America & 2.56 & 2000 \\
\hline Sweden & 3.28 & 2002 \\
\hline France & 3.37 & 2004 \\
\hline
\end{tabular}

Source: World Health Organization Core Health Indicators

NATIONAL INSTITUTIONS AND OFFSHORING OUTCOMES

\section{$\underline{\text { United States }}$}

\section{Institutional terrain}

In contrast to what we term professional bureaucracy in the UK and a public healthcare system in Singapore, in the US healthcare can be characterized as a managed exchange system. This system has traditionally enabled professional dominance over education, certification, and medical practice. The historical autonomy held by American physicians has been counterveiled by governmental regulation, and more recently, by a managed care environment exerting managerial supervision over physicians, but physicians have not lost the core elements of their autonomy.

Governmental influence over the medical profession in the U.S. works primarily through funding and reimbursement policies, subsidization of medical education, and legislation. Various government agencies supply $46 \%$ of the reimbursement for healthcare costs to physicians. But policies can have a wider impact outside the services directly funded by government agencies. For example, when Medicare, the agency that funds elderly care, decides on its reimbursement rates, other insurers follow suit, resulting in a larger diffusion of Medicare practices. Because the majority of U.S. physician earnings are based on fee-for-service, reimbursement rates set by insurance companies, particularly the ratio of reimbursement for technical equipment vis-à-vis 
professional service (e.g. physician labor), greatly affect physician earnings. Thus, physician groups lobby congress to influence government reimbursement rates.

The question of interpreting government reimbursement policies also deters physicians from practices that are too novel and thus where application of existing laws is not straight forward. For example, Medicare regulations ban the reimbursement of medical services provided outside of the U.S. This regulation, which was initially introduced to discourage American patients from getting treatment in Mexico, acted as a deterrence for providing full radiology reports from outside of the U.S. We return to this issue later.

In addition to the deterrence effect of governmental policy, the managed care environment has affected incentive structures for physicians. Managed care came out of a movement to contain the rising cost of healthcare in the late 70s and early 80s (Scott, 2004). Although there are variations of managed care, managed care organizations typically oversee costs and quality of service by choosing those physicians who exercise price-sensitive restraint in their clinical decisions and show acceptable quality records (Fine \& Sunshine, 1986). In return, managed care organizations supply physicians with a network of patients and administrative support. In 2005, $88.5 \%$ of all physicians were contracted with some form of managed care organization (O'Malley \& Reschovsky, 2006). ${ }^{6}$

Despite changes in the healthcare environment in recent decades, American physicians still control the education and training of those who seek to enter their profession, and essentially determine who gets certified as a physician. America's healthcare fee schedules have assured that physicians are among the highest paid in their profession world-wide. The profession's umbrella organization, the American Medical Association, as well as separate associations for medical specialties, are effective tools for unified collective action and political lobbying. These associations publish standards and guidelines to shield their members from reduced reimbursements, new legislations, and competition from other medical occupations.

\footnotetext{
${ }^{6}$ This was a small but significant decrease from 92.6\% in 1997. Despite public conjectures that physicians would drop out of managed care insurance networks in large numbers due to their low payment rates and administrative burdens, the decrease in the proportion of physicians contracting with them was minimal (O’Malley and Reschovsky 2006: 1).
} 
Below we discuss how, faced with increasing demand for services that they couldn't meet, radiologists condoned outsourcing, but devised strategies for doing so without undermining their control over the work. American radiologists were able to continue exerting control over their work through discretionary use of regulation as well as normative control over their own peers.

\section{Diagnostic Radiology in the U.S.}

Diagnostic radiologists in the U.S. today are engaged in an ongoing effort to maintain control over their work. These efforts include mastering changes in technology, defending their occupational jurisdiction from other specialists, and using the managed care environment to promote their occupation. Overall, diagnostic radiologists have been successful in these initiatives.

American diagnostic radiologists are not new to dealing with changing technology in their work. In $1995,34 \%$ of radiologic procedures and $73 \%$ of the relative value units ${ }^{7}$ performed by radiologists were in fields that had not existed or were only emergent a generation earlier (Margulis \& Sunshine, 2000). During the history of their profession, diagnostic radiologists have maintained control over knowledge of changing technology. This knowledge has been essential in guarding the boundaries of their work from other specialists, for in the absence of regulations governing occupational boundaries within the medical profession, practice has determined these boundaries.

With digitization and better quality scans, the interpretation of radiologic images became more accessible to other specialists. A study of Medicare reimbursements in 1989 found that nonradiologists performed 25\% of all radiologic work. Cardiologists provided the largest threat to radiologists’ territory, performing 10\% of all radiologic work (Sunshine, Bansal, \& Evens, 1993). Radiologists have fought the "turf war” in multiple ways. Strategies advocated by the American College of Radiology (ACR), the largest trade association for radiologists, included: i) fortifying radiologist residents' training in sub-specialties; ii) mounting a legislative lobbying effort against the practice of "self-referral” of diagnostic interpretation by other specialists; and iii) calling out to radiologists to strengthen their hold on the consultative aspect of their work, as opposed to the

\footnotetext{
${ }^{7}$ Relative value units, or RVUs, are a resource-based indicator for measuring physician work used by Medicare.
} 
diagnostic interpretive aspect. This latter initiative encompassed an effort by radiologists to reenforce their image as clinicians, and not as “image readers". One article written on the subject by radiologists specifically warned of the threat provided by the use of digitized technology on radiologists' identity: "It would be a great loss to the profession if radiologists were to be identified by other physicians and patients only as image readers sitting exclusively in front of workstation screens and ceasing to be clinicians." (Margulius and Sunshine 2000: 17)

Managed care provided radiologists with a new environment in which to prove their occupation relevant. On the one hand, managed care plans provided radiologists with an opportunity to fight off other specialists' incursions into their work. In some cases, radiologists could convince managed care organizations that only radiologists, and not other specialists, could make costeffective decisions over scans because of their superior knowledge of diverse radiologic equipment. On the other hand, the managed care environment changed the way radiologists traditionally worked. Managed care also changed the organizational form under which radiology is performed. Under managed care, insurers preferred to contract with one large multispecialist provider (preferably the lowest bidder), who then subcontracted various specialty works to groups of practitioners. For radiologists, this meant that the traditional practice of radiology by a solo practitioner or in small groups has been abandoned in favor of practice in large groups or networks of radiologists who bid together (Sunshine \& Evens, 1994). ${ }^{8}$

The advent of teleradiology helped radiologists deal with the managed care environment, but could potentially hinder their efforts to defend their occupational jurisdiction. For this reason, radiologists sought to control its use. Remote diagnosis of radiological images precluded interacting with other specialists and communicating with patients, which radiologists considered integral to maintaining their occupational jurisdiction. In addition, there was growing awareness among radiologists that teleradiology had contributed to more radiological residents choosing interventional radiology over diagnostic radiology due to fears that teleradiology would shrink the job market in diagnostic radiology by the time they graduated (Margulis and Sunshine, 2000: 17).

\footnotetext{
${ }^{8}$ Surveys of radiologists showed that the proportion of radiologists in solo practice or in groups of two to four has decreased between 1995 and 2000 from 25\% to 21\%, and those in groups of fifteen or more increased from 30\% to $38 \%$ in the same period (Sunshine et al 2002).
} 
Thus, the profession sought to control the use of teleradiology in various ways. First, radiologists have limited using teleradiology for outsourcing to night time work and excess day-time work. Teleradiology provided radiologists a cost-effective way to provide their services by consolidating work across several clients. This was especially appreciated for night-time work, which radiologists considered onerous and detrimental to a healthy life style. Teleradiology is still mostly used for preliminary consultations among radiologists practicing in the same group rather than for outsourcing purposes - a survey carried out by the ACR in 2003 found that $79 \%$ of radiologists surveyed said they used teleradiology, but only $15 \%$ of these respondents said they used it with out-of-group radiologists (Goelman 2005: 99-100). Second, professional norms, which are re-enforced via guidelines published by the American College of Radiologists, prevent teleradiology firms from contracting with hospitals in a way that undermines the hospitals' inhouse radiologists. ${ }^{9}$ This includes requiring that radiologists providing outsourced services be board certified in both the transmitting and receiving states (www.acr.org). Most often, the hospital that orders the services additionally requires that radiologists transmitting teleradiology reports go through its in-house accreditation procedure (Goelman 2005). Lastly, despite the capacity to deliver full reads, teleradiology firms often limit their services to preliminary reads that require the in-house radiologist in the ordering hospital to sign off on the final report. Such a practice is in part a response to potential regulatory complications in case of malpractice allegations; it is also meant to deal with Medicare bans on reimbursement of work done outside of the U.S. However, the widespread practice of using teleradiology for preliminary reads instead of full reads indicates that radiologists have sought to control the use of teleradiology to ensure their collective interest is not hurt.

\section{Offshoring Diagnostic Radiology from the United States}

The emergence of new forms of organizing radiologic work around teleradiology was a precursor to offshoring. Offshoring work abroad involved many of the same set-ups as those needed for establishing teleradiology firms; these included hardware and software configurations

\footnotetext{
${ }^{9}$ Another informant Goelman interviewed who worked at the largest night-time provider of teleradiology services explained it this way:

We talk to the radiologist, and we will not proceed if the radiology group in the hospital will not say 'yeah we want to go ahead.' Because we are radiologists, at least the founders are radiologists, and we will not go behind the group to underbid their services to hospitals. (Goelman, 2005: 121)
} 
and administrative provisions for acquiring board certification in multiple states (Wiley, 2005). Teleradiology firms found that they could gain time-zone advantage by sending their radiologists to offshore places to interpret scans taken during the night in the U.S. Some teleradiology companies have set up formal operations, establishing overseas branches and radiological centers abroad, while other companies have left it up to individual radiologists to exercise the choice of moving to another country. Besides the lifestyle attractions to the American radiologists of working in places such as southern Spain, Switzerland, and Australia, teleradiology firms have argued for quality benefits from doing night-time reads during the day time abroad (Kalyanpur, Weinberg, \& Nklesa, 2003).

The notable exception to the predominant model of U.S. teleradiology firms sending their own (U.S. board certified) radiologists to offshore places is the less frequent practice of U.S. hospitals contracting directly with teleradiology firms located abroad, including a teleradiology firm established in India. The latter pattern of offshoring work has been placed under considerable scrutiny by the profession as well as the American media (Pollack, 2003). In addition, overseas teleradiology firms with no ownership ties to a U.S. firm find it difficult to obtain U.S. malpractice insurance, which makes it risky for American doctors to refer diagnostic reads to these firms. In the last section of the paper, we discuss how an experiment by a U.S. hospital to contract reads to a teleradiology entity in India whose radiologists were not U.S. board certified came under severe criticism and was curtailed prematurely. Thus in the U.S., the profession has been able to control offshoring to prevent it from threatening its occupational jurisdiction in a similar way that it has controlled the use of teleradiology within the U.S.

The U.S. government has influenced offshoring practices mainly through deterrence rather than direct policy intervention. As mentioned previously, the Medicare policy that bans reimbursement of medical services performed abroad was devised with U.S. patients getting treated overseas in mind. However, teleradiology companies sending their radiologists abroad cited this policy as the reason why they only provided preliminary reads from these locations (Goelman 2005). In addition, participants in teleradiology believed that legislative action would soon prohibit the transfer of patient data abroad (Wiley 2005).; to date, this legislation has not been initiated, but we believe that the threat of legislation discourages offshore teleradiology. 
Thus, for the foreseeable future, radiologists' lifestyle and quality of work reasons have more to do with why diagnostic radiology work is sent abroad than cost-related issues.

\section{United Kingdom}

\section{Institutional Terrain}

The U.K. health system has, for decades, been governed by a single public agency, the National Health Service (NHS). We characterize the U.K. healthcare system as a professional bureaucracy; by doing so, we are agreeing with a widely shared view of the NHS that draws on Mintzberg (1979) and Mintzberg and Quinn (1991) to describe a formalized organization governed by expert authority (Harrison, 1992; Klein, 1998; Peckham, 2003). Scholars generally agree that the power of health care professionals, among whom physicians occupy the helm, was guaranteed in the original institutional configuration of the NHS upon its inception in the 1930s. Subsequent re-organizations of the NHS, such as the re-tooling of 1974, the quasi-market reforms under the Thatcher administration, and the recent Labour administration reforms, have challenged the nature of professional control, but as we discuss in this section, have not altered it altogether. The medical profession today in the U.K. still holds expert authority over the NHS system. The reforms could not have taken place without the cooperation of the medical profession (Klein, 1998; Le Grand, 1999); moreover, reforms designed to curb physician power have arguably been the least successful.

In recent decades the NHS system has had difficulty responding to an essential dilemma: how to continue providing timely and affordable universal care in the face of increased demand. This dilemma is perhaps most succinctly represented by the problem of long wait lists for treatment, a problem that both the Thatcher reforms and Labour programs have tried to address but that has remained unresolved. Increasingly, professional discretion has come under question as the 1 million patients on the wait lists have been interpreted as the product of a rationing system based on the discretion of medical personnel. Klein, a scholar who conducted research on NHS reforms, pointed out the symbolic character of wait lists in influencing perceptions of the system's overall success: 
"If rationing by exclusion is the hallmark of the US system, rationing by professionally defined need is the distinguishing characteristic of the NHS; that is, if the 40 mill uninsured Americans are a symbol of the US system's shortcomings, the more than 1 mill Britons on waiting lists are the symbol of the NHS's shortcomings." (Klein 1998:112).

Waiting lists have become a political liability to a succession of governments whose attempts to address the problem are largely seen as having failed. Klein goes on to point out that though other issues may be more central to what needs to be improved in the health system, what placed waiting lists at the top of reform agendas was its political impact:

"Although waiting lists are in many respects a misleading measure of the NHS's performance, and there are many more urgent claims on resources, the thwarted attempts of successive govts to reduce them have only served to add to their political importance." (Klein 1998:123)

Although there are important differences between the NHS reforms under the Conservative and Labour regimes in 1991 and 1997 respectively, observers agree that there is more continuity than discordance across the reforms (Harrison, 1992; Klein, 1998; Le Grand, 1999). Three features are common in both the Conservative and Labour reforms. These three features of the reforms in the NHS system opened the way for NHS providers to subcontract services to independent service providers in the private sector as well as to offshoring. However, at the time of our research, neither the success of each of these reforms (with the possible exception of changes in government control over certification) nor the plan to subcontract NHS services was guaranteed.

First, reforms sought to introduce managerial authority as a check on professional authority in the NHS system ${ }^{10}$. Providers were given budgets to maintain, and managers kept account of performances. However, NHS budgets were seldom reduced, and holding professionals accountable for their performance was relatively rare.

Second, reforms introduced contracting among health authorities and providers through the establishment of an "internal market” modeled on the managed care system in the U.S. Local health authorities played the role of purchasers, and large providers (or groups of providers) became independent trusts contracted with the health authorities. Incentives were built into the trusts to promote efficiency. Thus, trusts could make their own investment decisions and keep

\footnotetext{
${ }^{10}$ Cite figure on increase of managerial staff in the NHS viz professional staff and nursing staff (Peckham \& Exworthy).
} 
their profit. However, government guidelines ensured that providers take societal interests into consideration in making their investment decisions. For example, uuntil recently, providers were prohibited from using their profit to increase salaries, which are still determined largely by the government (Klein, LeGrand). We return to the issue of physician remuneration below when we discuss the implications for outsourcing in radiology.

Unlike the first two characteristics of reforms, steps taken to centralize and increase government control over certification are likely to impact professional power by changing the relative supply of domestic and foreign medical professionals. While in the past, professional associations had largely run the system of certifications, since the mid-90s certification has been charged to a central government agency, the Postgraduate Medical Education and Training Board (PMETB). Relevant professional medical associations retain the right to set standards and "recommend" certification to the PMETB in their specialty. While the primary aim of such changes were to standardize the qualification of professionals, an additional outcome of centralizing certification procedures has been that it has routinized the cross-certification of medical professionals trained outside of the UK, particularly with respect to medical professionals in other EU countries. Under the new system, professionals residing in countries outside of the EU could also register with the PMETB provided they passed additional qualification requirements.

\section{Diagnostic Radiology in the U.K.}

The waiting times for radiology services, both diagnostic and interventional, have come under increasing fire for delaying important treatments such as surgery (RCR response to BMJ article “Waiting for Radiotherapy”). In order to alleviate the pressure on the NHS system, the government started outsourcing radiologic services to private sector companies employing private sector medical professionals. In 2004, the government spearheaded an NHS-wide reform program that included outsourcing radiologic scans taken at NHS hospitals to an independent service provider (ISP) in the private sector. ${ }^{11}$ In June, 2004, the first such bid, which included outsourcing of scanning as well as diagnostic reading, was awarded to Alliance Medical, Ltd., a private sector company that had been providing services to NHS in the past. What distinguished this bid was its scale - the contract covered 5 years of service for 95 million pounds. Alliance, in

\footnotetext{
${ }^{11}$ Notably, this reform came hand in hand with a raise in salaries for professionals employed by the NHS.
} 
turn, subcontracted this work to multiple radiologic centers. Some of these were teleradiology centers located in other EU countries as well as one in Australia; in addition, Alliance hired a limited number of NHS radiologists who worked under contract hours. Under the centralized certification system of the Postgraduate Medical Education and Training Board, foreign radiologists were eligible to apply for certification in the U.K. A radiologist obtained registration in the UK in three ways, two of which stipulate provisions for foreign radiologists to practice in the UK or deliver services to UK entities:

- The radiologist can complete medical training and pass certification examinations in the U.K. The PMETB, with advice from the Royal College of Radiologists (the national specialist organization) will then award a Certificate of Completion of Training. With the certificate, the radiologist can apply to be entered in the Specialist Register of Radiologists.

- A radiologist certified in another E.U. country can apply to have their credentials reviewed by PMETB and a Committee of the Royal College of Radiologists. This review is relatively pro forma, a reflection of E.U. efforts to harmonize regulations across countries. A positive review allows the radiologist to petition to be entered into the Specialist Register of Radiologists.

- A radiologist certified outside the E.U. also must present their credentials to the PMETB and a Committee of the Royal College of Radiologists. This review is not automatic and credentials must include details of training and work experience, references, publications (if any) and so on. If the credentials are approved, the radiologist can petition to be entered into the Specialist Register of Radiologists. ${ }^{12}$

The first wave of subcontracts elicited a strong reaction from NHS radiologists. First, according to our informants, NHS radiologic units became more efficient, presumably in response to a perceived threat to their domain. Second, other NHS specialists were reluctant to refer their diagnostic reads to Alliance. The insufficient referrals explained why the guaranteed contract level (5 years of service for 95 million pounds) went unfulfilled, and why in a second wave of subcontracting, the government did away with guaranteed business levels. Third, the Royal College of Radiologists (RCR), the largest professional association representing close to 7,000 radiologists in the UK, raised quality concerns with subcontracted work and audited the independent service provider ${ }^{13}$. Thus, in the second wave of contracts awarded in 2006, the

\footnotetext{
${ }^{12}$ Review committees appear to have discretion (rather than fully specified guidelines) in making their decisions. See http://www.rcr.ac.uk/index.asp?PageID=733

${ }^{13}$ The audit did not find any of the examinations done by the independent service provider to be so problematic as to be ordered for re-examination; nevertheless, the audit raised concerns within the NHS and the Department of Health
} 
government did away with guaranteed business levels. During the implementation of these awards, the Gordon Brown administration, a more left-of-center government in its outlook, took office and cancelled several of the contracts which had been awarded under the Tony Blair administration. Assessing our informants' testimonies, we conclude that the teleradiology firms participating in the second round subcontracting agreement are not receiving much NHS business.

\section{Offshoring diagnostic radiology from the U.K.}

Despite significant domestic reforms in the past two decades, we find that offshoring is governed by the same "implicit concordat" between professionals and government that constitutes the system of professional bureaucracy in the U.K. (Klein, 1998) It is true that professional authority has been challenged over the period of the reforms, but had it stayed the same, it is unclear that radiologists would have been able to prevent offshoring of their work. In theory, the interdependence of the state and the medical profession under a professional bureaucracy opens the possibility of larger scale offshoring in the U.K. compared to the U.S., where professionals have more power. In particular, two aspects of the professional bureaucracy enable offshoring arrangements. The first is the willingness of the state to intervene to alleviate public need and advance its political interests. We see this in the way that the U.K. government initiated measures to abate capacity shortages in the public sector and took control over the certification system. The second is the incentive structure for professionals under a professional bureaucracy. Because NHS radiologists were salaried by the NHS until only recently and there is no independent fee-for-service structure, radiologists in the UK are not directly hurt by subcontracting or offshoring, and, aside from quality concerns, have no direct economic interest in opposing work from going to the private sector or going abroad. Importantly, the recent subcontracting of radiologic services was accompanied with salary raises for NHS radiologists. No NHS radiologist lost his/her job to subcontractors, whether involving foreign or U.K. radiologists, and none is foreseen to be lost in the near future. 
But in practice, even in an institutional structure where professionals are incentivized to cooperate with government initiatives, outcomes from the two waves of subcontracting of NHS radiology services show that even when professionals are not economically incentivized to oppose outsourcing, they are reluctant to cede control over their work. In addition, for foreign radiologists supplying services from outside the EU, a potential obstacle is the EU directive that prohibits sending patient data to any non-EU country that lacks adequate protections in the transfer of personal data unless the provider obtains consent from the patient. ${ }^{14}$

\section{Singapore}

Institutional Terrain and Diagnostic Radiology in Singapore

Singapore's healthcare system portrays the characteristics of a public healthcare system. In Singapore, the public sector still provides roughly 80 percent of the nation's total healthcare; there have not been any major market-based reforms similar to those in the UK; and professionals in the public sector do not have much discretion in the allocation of resources. Historically, the institutional logic governing healthcare, like many other aspects of the Singaporean state, has been that ensuring citizen's health is part of the responsibility of the developmental state. The government ultimately sets price guidelines and operative directions for public sector providers.

Singapore has faced similar dilemmas of capacity shortage as the U.K. over its history due to rapid population growth, an aging population, and patients from abroad who seek medical treatment in Singapore. According to Singapore's health ministry, the number of foreign patients seeking treatment in Singapore has increased by an average of 20 percent during 2004-2006; the largest number of patients come from nearby Indonesia and Malaysia, but some come from the Middle East, China and Vietnam (Khalik, 2006; Lee, 2006).

\footnotetext{
${ }^{14}$ See the EU Directive on Data Protection, Articles 25 and 26, http://www.cdt.org/privacy/eudirective/EU_Directive_.html\#HD_NM_45
} 
Diagnostic radiology in Singapore faced two related chronic problems. One was that due to the emphasis on universal coverage at the cost of investing in new technologies, Singapore had not yet fully transitioned to digital radiography (Lee, 2006). X-ray slides were still being motorcycled from hospitals to radiologists and back. In contrast to the conventional X-ray segment however, Singapore was an early purchaser of CT and MRI technology. Secondly, due to technological impediments as well as growing demand, wait times for $\mathrm{X}$-ray reads classified as non emergency cases were getting longer, particularly for Singapore's secondary public healthcare institutions, called "polyclinics".

In 2004 the government responded to both issues with a reform program in healthcare. Though the program was aimed at enhancing healthcare in general, most of the funds were allocated to a \$2.3 million investment to equip all of Singapore’s polyclinics with digital technology, accompanied by a plan to outsource low value added radiology work, mostly X-ray reads, to an Indian firm. In addition to the goal of improving patient care at home, the government's program to reform Singapore's healthcare was based on an explicit strategy, expressed in ministry statements and newspaper op-eds, to build the nation's comparative advantage in healthcare. In government statements, officials discussed healthcare as an industry, following finance and petrochemicals, that would boost Singapore's economic performance in the global market. This included plans to attract more foreign patients to get treatment in Singapore, as well as to provide telemedicine services to hospitals abroad.

In order to carry out the goals of the reform, the government perceived a need to concentrate its resources in higher end radiologic work (CT and MR services), as well as to grow its workforce in healthcare. The Singaporean government sought out India as a destination for outsourcing Singapore's low-value radiologic work (mostly X-rays and ultrasonography) so that Singaporean hospitals would free their capacity to serve domestic and foreign needs for higher value added radiologic interpretations. In an effort to augment its workforce in healthcare, the government increased the number of foreign universities that the Singapore Medical Council would accept credentials from, from 71 to 100 universities. As of March, 2006, Singapore had 6,640 registered physicians, of whom 1,300 had earned degrees from outside of Singapore (Khalik, 2006). 
The government's reform program showed the commitment of the Singaporean state to continue to provide quality universal care to Singaporean citizens through its public sector. Despite the fact that 80 percent of Singapore's healthcare is provided by public sector providers, only about two-thirds of Singapore's healthcare professionals are employed in the public sector. While private sector healthcare was booming with cash inflows from the treatment of overseas patients, public healthcare lagged behind in investment and technological change. A recent speech by Minister Mentor Lee Kuan Yew, made on the occasion of Singapore General Hospital's $185^{\text {th }}$ anniversary in April, 2006, stressed the importance of having the public sector lead innovations in healthcare. His speech also revealed the high profile support that the government had mobilized for healthcare reform in the public sector:

If new medical advances are found only in our private sector, there will be an exodus of talent to the private sector and public health care standards will degrade. Singapore has been unique in maintaining a public sector with standards of medical care often superior to the private sector. We must retain a good part of our medical talent in our public sector and so keep an adequate share of our senior and experienced consultants. ... The public sector must provide good, high-quality care at affordable prices. (The Straits Times Singapore, April 17, 2006)

The recent move for the Singaporean Ministry of Health to outsource diagnostic reads to India and to enter the global teleradiology industry was very much couched in the rhetoric of government responsibility to provide affordable care for its citizens. In this way, the logic of Singapore's public healthcare system extended to its recent reforms and to its offshoring practices.

\section{Offshoring Diagnostic Radiology from Singapore}

The offshoring of diagnostic radiology from Singapore was from the onset a targeted, strategic action planned and executed by the Ministry of Health with the expected cooperation from Singapore's radiologists. The government sent and received multiple teams of delegations to various Indian firms before it awarded an initial contract to one Indian firm, which we call RadIndia. ${ }^{15}$ An initial three-month contract was signed for RadIndia to provide X-ray reads to one polyclinic in Singapore. It was expected that this contract was the precursor to larger-scale offshoring of low-value radiologic work.

\footnotetext{
${ }^{15}$ The government's research on feasible arrangements was based on already existing practices of teleradiology provided by Indian firms to Singapore's private sector.
} 
The planned multi-phase contract raised an outpouring of debates that played out most prominently in the op-ed pages of The Straits Times Singapore in March, 2006. Radiologists from both the public and private sectors criticized the ministry for using public funds to ship out work to India. These radiologists argued that had the ministry invested the \$2.3 million to set up a teleradiology scheme that utilized radiologic centers in Singapore's tertiary health institutions, the government's aim to provide “cheaper, faster, quality” radiology services would have been met domestically. Radiologists raised two chief concerns: quality control and impeded skills development for Singapore’s radiologists. Several of the radiologists writing in the op-ed columns made explicit references to U.S. regulations that require radiologists abroad to be U.S. board certified and obtain malpractice insurance, and argued for similar quality standards to be enforced in Singapore for offshored radiology. One radiologist's writing on this issue is representative of many others' who wrote in a similar vein:

The quality of radiological care is highly controlled in various countries, especially in the US. Interpretation of radiological examinations is permitted only by radiologists who are US board-certified, state licensed and have U.S.-accepted malpractice insurance. ... Can MOH ensure rigorous audit of these foreign radiologists, review their specialist accreditation bi-annually and ensure patient data protection? It would be wrong to apply double standards in the name of cost saving. Singapore radiologists need to be given the support and to be allowed the administrative control necessary for them to provide timely, quality care for their patients. If we want 'more, better, faster' then we have to be willing to invest adequately, appropriately and locally. (Kit, The Straits Times, March 10, 2006)

But the relatively muted response of the College of Radiologists, Singapore's professional association for radiologists, which issued a statement that essentially held up both sides of the debate on offshoring, paved the way for the ministry to continue with its plan (The Straits Times, March 15, 2006).

The Ministry of Health responded speedily (almost too speedily) to objections and firmly held its ground. On March 6, four days before the radiologist above wrote his statement, the $\mathrm{MoH}$ announced that it had appointed Singapore's College of Radiologists to determine RadIndia's “suitability”, and that a delegation of College members, upon visiting RadIndia’s facilities, had proclaimed the firm capable of receiving accreditation in Singapore. MoH then set general guidelines for offshoring that included an assessment of the overseas provider by Singapore's professional association in the respective field; a rule that the Singaporean entity outsourcing services to overseas providers will ultimately be accountable for the quality of services; and a 
promise that the $\mathrm{MoH}$ will conduct regular randomized quality tests and audits of all radiology reads. ${ }^{16}$ Having responded in this way, the $\mathrm{MoH}$ proceeded to extend the pilot contract with RadIndia to cover X-ray reads for all nine of Singapore’s polyclinics.

But MoH's plan included more ambitious aims beyond sourcing teleradiology from India. $\mathrm{MoH}$ planned to use India's knowhow in the global teleradiology market for its own entry in this market. In the summer of 2005, the MoH announced that Singapore's National Health Group, one of two health provider groups in the public sector, was entering a joint venture with RadIndia to jointly enter global tenders in teleradiology, including those that the entities expected would be given out by large healthcare organizations in the U.S. Ministry officials, in interviews with the media, spoke of Singapore's free trade agreement with the U.S. and the National Health Group's reputation for quality putting it in a favorable position for this venture. The minister is quoted to have said, "Imagine, if we had been working on teleradiology as actively as India has over the past few years, we would have been very well positioned to tap this major economic activity” (Khalik, 2005).

Singapore's state driven public healthcare system, then, provides a case where offshoring was used by the developmental state as an incentive to upgrade its technology. The influence medical professionals had over this process was limited to public discourse; ultimately, in this model, the state has the power to architect the design of offshoring as well as bring about changes in the field of healthcare.

\section{Providing Diagnostic Radiology SeRVices from India}

We examine the provision of offshored services from India because it is frequently cited as the low-cost destination country for professional work by those who suggest that globalization forces will integrate markets in professional services as it did for manufacturing and back office services. In our study, only Singapore comes close to following this prediction, but even in the case of Singapore, the actor engaged in offshoring is not profit-seeking firms but the government,

\footnotetext{
${ }^{16}$ See, for example, http://www.moh.gov.sg/corp/about/newsroom/mediaforums/details.do?id=36601859
} 
and the motivation is certainly not cost-cutting. In this section we explore the Indian side of the story. The institutional make-up of Indian healthcare as well as the limited supply of Indian radiologists add to the difficulty of observing the conventionally predicted outcomes in the offshoring of diagnostic radiology. We trace the experiences of two firms and discuss the different outcomes.

\section{Institutional Terrain of Healthcare and Diagnostic Radiology in India}

India's healthcare delivery system is federated, with states setting their own public health policies. Large variations exist in the availability and quality of healthcare across states, and between urban and rural areas. For example, Uttar Pradesh had 735 hospitals in 1990 with a 1991 population of more than 139 million, while Kerala, with a population of 29 million, had 2,053 hospitals. Rapid population growth, coupled with the absolute scarcity of healthcare professionals who furthermore are reluctant to relocate to rural areas, means that the country has suffered from a chronic shortage of medical professionals (refer to Table 2 on p9). Primary healthcare centers, which act as first stops and points of referral to secondary and tertiary institutions, rely mainly on paramedics to deliver care. In recent years, with economic growth and the growth of the middle class in urban areas, a new for-profit system of hospitals and clinics has emerged. The for-profit sector has attracted a disproportionately large number of recent graduates of medical schools.

As with all medical specialties, radiologists are in shortage in India, and those eligible to provide services to the markets covered in this study are even fewer. In 2005, the national professional association for radiologists, the Indian Radiology and Imaging Association (IRIA), counted 5,500 registered and active radiologists for a population of 1.08 billion. ${ }^{17}$ This supply combines two tracks in diagnostic radiology that our informants have distinguished in terms of their different status in the field - the diplomas (DMRE \& DMRD) and the Medical Doctor (MD) and Diplomate in National Board (DNB). Although all of these degrees are graduate residency programs, the latter two degrees (the MD and the DNB) are rewarded by better positions in the job market. Our interviewees in India told us that companies engaging in offshore teleradiology

\footnotetext{
${ }^{17}$ By contrast, the American College of Radiology estimates about 27,000 U.S. radiologists for a country of 298 million.
} 
for advanced markets would be looking primarily to hire radiologists from the second, more prestigious track. As of 2006, there are 7,698 graduate resident seats for all medical specialties in institutions recognized by the Medical Council of India (MCI). But only 156 of these seats award an MD in diagnostic radiology and another 100 award a DNB in diagnostic radiology. ${ }^{18}$ In recent years, some newer and private sector Indian hospitals are foregoing the MCI accreditation process which they consider cumbersome; thus, there may be additional qualified radiologists than the 256 residency seats (MD and DNB seats combined). However, an increase by 256 radiologists per year minus retirements and a small number of Indian medical residents who migrate to other countries each year is not a large pool for global teleradiology, not to mention for India's own large population.

Formal and informal institutions of training make the kind of radiologists eligible to provide teleradiology services to advanced markets an even smaller pool than the numbers above suggest. Advanced markets such as the U.S. require teleradiology providers to have had the training to read multiple modalities (e.g. CT, MR, ultra sonography, nuclear radiology) and to recognize basic abnormalities in most regions of the body, all learned at an internationally recognized institution. Training to this standard requires extensive time spent working on a variety of expensive scanning equipment. In India, advanced scanning equipment, where available at all, may provide only limited access to medical students. Graduate medical education often emphasizes specialization in a particular scanning technology rather than the use of multiple technologies to investigate a particular body system. Specialization in particular scanning modes is also reinforced through organizational practices - our interviewees attest that hospitals and clinics often organize their radiology work around specific machines they have acquired.

In theory, a natural source of radiologists familiar with international standards would be returning Indian medical graduates who have completed residencies abroad, particularly in the U.S. The number of such returning graduates is very small, however. In 2001, one-fifth of all foreign-trained physicians practicing in the U.S. graduated from medical schools in India; many

\footnotetext{
${ }^{18}$ Official figures posted on Medical Council of India (http://mciindia.org/) and National Board of Examinations (http://www.natboard.nic.in/) websites.
} 
more physicians in the U.S. are of Indian descent (Forcier, Simoens, and Guiffrida, 2004). ${ }^{19}$ But within the U.S. there is fierce competition for the current 500 radiology residency slots and interviews suggest that the majority of Indian medical students in U.S. residencies choose a specialty other than radiology. ${ }^{20}$ For the few Indian medical students who do become U.S. board certified radiologists, the decision to return to India rests on considerations of life style, values and career development.

In sum, India’s success in teleradiology hinges on Indian firms’ abilities to attract and retain qualified professionals from a limited domestic pool as well as to repatriate Indian medical professionals practicing in other countries.

\section{Providing Diagnostic Radiology Services from India: Two Suggestive Models}

During the first author's first trip to India, she was able to informally survey Indian firms engaged in teleradiology. This allowed us to quickly identify two firms in southern India who provided services separately to the U.S., UK and Singaporean markets. While there may be other Indian firms doing reads for hospitals in the U.K. and Singapore, as far as we were able to identify, these two firms were the only Indian entities who were engaged in providing some form of legitimate teleradiology services to the U.S. market. What distinguished both of these firms was the entrepreneurial spirit of the people involved, their capacity to study the institutional frameworks in each of these markets, and their ability to recruit and retain medical professionals with the skills to do the work. These commonalities aside, in many ways the two firms provide two quite different models.

\section{$<$ DiagnosIndia $>$}

The first firm, which we will call DiagnosIndia, is part of a large Indian conglomerate that partnered with a medical hospital group in India. The large Indian conglomerate brought

\footnotetext{
${ }^{19}$ To practice in the U.S., a graduate of a foreign medical school must do their medical residency in a U.S. program and pass U.S. medical boards. About one-fifth of U.S. medical residents (all medical specialties) attended medical school outside the U.S.

${ }^{20}$ The competition reflects high radiologist salaries and the fact that a radiologist has reasonable control over his or her hours.
} 
financing and managerial skills to the venture, while the medical group provided the Indian radiologists. DiagnosIndia attempted to recruit Indian medical graduates returning from the U.S. with a U.S. board certification, but this attempt failed due to many of the difficulties we mentioned. Without the possibility of its reads being reviewed by a U.S. board certified radiologist based in India, DiagnosIndia could not obtain malpractice insurance. Without malpractice insurance, the firm could not attract customers and so DiagnosIndia discontinued the service.

Instead of diagnostic reads, the firm then turned to providing three-dimensional (3D) reconstruction of digital images. 3D reconstruction is the process of combining two-dimensional CT, MRI or ultrasound "slices" into a virtual three-dimensional model that a doctor would use to highlight pathology on the surface of the brain, the heart, or another anatomical area of interest. ${ }^{21}$ In the U.S., the person doing this work typically begins as an experienced CT/MRI technician who receives 6 - 9 months of additional training in software use and human anatomy. In DiagnosIndia, Indian radiologists, aided by technicians, were put to the task. This business did not generate much profit for DiagnosIndia, as presumably the U.S. client was paying prices similar to U.S. technicians' wages, while DiagnosIndia had incurred start up costs and was paying its radiologists salaries much higher than Indian levels. Interviews suggest that the radiologists doing 3D reconstruction felt well remunerated but at times found their work monotonous.

Around the same time, the Indian medical group partner of DiagnosIndia, which we will call MedIndia, learned of opportunities created in the UK market through the large government contract awarded to Alliance. DiagnosIndia, through Indian radiologists in the UK who acted as their contact and later worked for them, established a branch office in the UK and became one of Alliance's subcontractors. At the time of our study, this branch office only employed UK trained and registered radiologists to do the Alliance work. But some Indian radiologists from MedIndia

\footnotetext{
${ }^{21}$ A "slice" refers to a cross-sectional image of the brain, abdomen, or other body region. The power of CT and MRI is their ability to produce a single cross-sectional image rather than superimposing multiple cross-sections as in a standard X-ray. A good introduction to 3D imaging can be found at the web site, www.slicer.com.
} 
were being sent to this branch to obtain training and a U.K. registration in preparation for the next phase of government tender for teleradiology. MedIndia harbored long term plans to bring back these radiologists trained and registered in the U.K. and have them read Alliance's scans from India.

Interviews with MedIndia’s top personnel in the radiology department suggest that MedIndia's motivation for participating in teleradiology practices for the U.S. and the UK, and for continuing its efforts to recruit U.S. board certified radiologists includes an educational goal. MedIndia owns several universities and teaching hospitals both in and outside of India. The head of the group's radiology department believes that if younger Indian radiologists can work with U.S. board certified radiologists, the experience will push Indian training toward the U.S. model - specialization in particular anatomical systems studied with multiple modalities. Building on the radiologists’ experience in working with U.S. customers, MedIndia plans to move to restructuring radiological departments in its hospitals across the country, and eventually to help diffuse systems-based specialization through its medical schools. The plan represents a frequently seen process in globalization: a developing country embracing the pressure to conform to international standards as a way to upgrade its own practices. ${ }^{22}$ In this case, teleradiology may change Indian radiology practice even though it does not increase physician access to scanning equipment.

DiagnosIndia's experience shows that for new entrants to the teleradiology market from developing countries, learning and overcoming the institutional barriers to practicing teleradiology can present a challenge. Failing to obtain institutional legitimacy in the U.S. market, this firm was forced to subject its radiologists to what they considered low status work in their profession. Despite DiagnosIndia having started as a business venture, its business model has been relegated to a low profit model, at least for now.

$<$ RadIndia $>$

\footnotetext{
${ }^{22}$ See Srinivas (2004), which includes a description of how Indian pharmaceutical firms used international generic drug standards in a similar way.
} 
The second firm we studied is RadIndia, the Indian company we earlier mentioned partnered with the Singaporean Ministry of Health. It is headed by two U.S. board certified radiologists who returned to India for personal reasons after training in the U.S. Both radiologists obtained their initial graduate training in India. When the senior member of the pair first returned to Bangalore, he retained his post as faculty at a major U.S. teaching hospital as he began to establish his teleradiology business. He published an analysis of his service in an academic journal that demonstrated the productivity gains that could arise from exploiting the time difference between the U.S. and India. Since our interviews, a third U.S. trained, board certified radiologist has joined the firm. The firm expects that more U.S. board certified radiologists will join the practice in the near future.

RadIndia does two kinds of reads for the U.S. market - night-time reads done in India during its daytime, and a smaller number of daytime reads done by U.S.-based radiologists employed by the firm. RadIndia also employs a number of India-certified radiologists who serve multiple roles. They assist U.S. board certified radiologists in U.S. work (much as radiology residents assist attending radiologists in a U.S. hospital) and they work independently on images from India and from countries other than the U.S. At the time of our study, RadIndia had some fifty hospitals across fourteen U.S. states as regular clients, sending X-rays, CT scans and MRIs. Due to the privileges retained by the U.S. board certified radiologists from their former U.S. employers, the firm is covered by malpractice insurance and thus provides full reads to U.S. hospitals rather than the customary preliminary reads provided by standard teleradiology services operating in the U.S. Partly as a result of the founder's commitment to giving back to Indian society, the company provides affordable teleradiology services to Indian hospitals in the local area as well as in more remote parts of India.

RadIndia's charges for its U.S. reads range from half to two-thirds of what similar work would cost at a U.S. hospital (Velloor, 2005). It pays returning radiologists the lower end of U.S. and U.K. salary scales, and it pays its India-trained radiologists roughly double what their compatriots earn. The pay, coupled with the opportunity for skills development and benefits of working in a high-performing, collegiate atmosphere are cited by Indian radiologists as reasons 
for wanting to work there. ${ }^{23}$ Reportedly, the waitlist of young qualified Indian radiologists for RadIndia’s positions is long.

As a result of its partnership with Singapore’s National Health Group, RadIndia has recruited one hundred additional India-trained radiologists housed in the firm's new 100,000 square feet complex. This center is equipped to provide diagnostic reads as well as $3 \mathrm{D}$ reconstruction services for markets as diverse as the U.K., the Middle East, Singapore, and other Asian countries.

RadIndia's experience shows that possessing the skills to acquire the institutional accreditation of client countries and hospitals leads not only to a higher profit model of business, but also a model that boosts the careers of professionals who join the company. The organizational structure of RadIndia - a company founded and run by radiologists - also contrasts with that of DiagnosIndia, which was managed by an Indian conglomerate that had provided the initial investment. These two models provide a starting point to understanding the challenges to providing professional offshored services from a country like India, as well as the strengths and weaknesses of different strategies to overcome these challenges. Perhaps more importantly, these models raise the difficult question of harnessing the benefits of offshored services for economic development in India. Educational upgrading for India’s profession of radiology is one potential benefit for Indian society. But the fact that radiologists employed by these two firms are some of India’s best qualified doctors who are needed by its own population poses important policy dilemmas for developing countries.

\section{DISCUSSION}

In this paper, we examined the role of national institutions in offshoring a particular kind of professional service work. In each of the countries, national institutions governing healthcare were changing - particularly in the United States and the United Kingdom, reforms have

\footnotetext{
${ }^{23}$ RadIndia radiologists read scans taken with a wide range of modalities, a scarce opportunity for most Indian radiologists. The firm places a high importance placed on quality - RadIndia has a track record of 99.8 accuracy in its reports, compared to the U.S. requirement of 96 percent.
} 
introduced market principles into areas that have hitherto been governed by professional authority. However, recent changes have failed to change core logics affecting healthcare organization in these countries, and particularly with respect to the relationship between professional authority and the state. Patterns of offshoring diagnostic radiology manifested in the United States, United Kingdom and Singapore could have been predicted from understanding the extent to which professional control over healthcare was upheld by the medical profession's relationship to the state in the original institutions prior to reforms.

The diagnostic radiologists we study in this paper are powerful - they dominate knowledge in a specialized medical field, and they are high in demand and low in supply. While they may be involved in jurisdictional fights, they are far from threatened, nor do they differ from other specialties in having to defend their territory from changing technologies and work practices. But importantly, radiologists' professional power is contingent on their position vis-à-vis the state in the healthcare system. As collective actors, they are able to exercise far greater agency in a globalized era than manufacturing or back office workers, yet their agency has to be sanctioned institutionally.

Seen from the point of view of firms supplying the work, professional services add another dimension to an already asymmetric relationship between buyers and suppliers - that of acquiring institutional legitimacy in the client country. We have shown that differences in the availability of technology, in training and work practices, and most importantly, discrepancies in certification (and, in the case of the U.S., malpractice insurance practices) potentially impede developing countries in engaging in offshored professional services on a large scale.

Lastly, one should note that while the distinctions we draw between professional services and manufacturing work contribute to building a nuanced theory of the offshoring of work, the details may vary across professions. In particular, whether professional dominance is supported by national or transnational institutions may explain variations in the professions' strategies for maintaining control over their work. Accountants, whose certification is reliant on international standards and whose practice increasingly is dependent on the convergence of national accounting practices to the Anglo-Saxon model, will take a different strategy to globalizing their work. As far as professional services in healthcare are concerned, institutional barriers are real 
and useful for professions, and as long as they differ across nations, globally integrated markets have yet to emerge for professional services.

\section{References}

Abbott, A. D. 1988. The system of professions : an essay on the division of expert labor. Chicago: University of Chicago Press.

Berger, P. L. \& Luckmann, T. 1966. The social construction of reality; a treatise in the sociology of knowledge ([1st ed.). Garden City, N.Y.,: Doubleday.

Campbell, J. L. 2004. Institutional change and globalization. Princeton, N.J.: Princeton University Press.

Campbell, J. L. 2007. Challenges for institutional theory: a response to Crouch, Streeck and Whitley. Socio-Economic Review, 5(3): 556-567.

Collier, R. B. \& Collier, D. 1991. Shaping the political arena : critical junctures, the labor movement, and regime dynamics in Latin America. Princeton, N.J.: Princeton University Press.

Fine, M. W. \& Sunshine, J. H. 1986. Malpractice Reform through Consumer Choice and Consumer Education - Are New Concepts Marketable. Law and Contemporary Problems, 49(2): 213-222.

Freidson, E. 1970. Professional dominance: the social structure of medical care ([1st ed.). New York,: Atherton Press.

Frieden, J. A. 1991. Invested Interests - the Politics of National Economic-Policies in a World of Global Finance. International Organization, 45(4): 425-451.

Friedland, R. \& Alford, R. R. 1991. Bringing Society Back In: Symbols, Practices, and Institutional Contradictions. In W. W. Powell \& P. DiMaggio (Eds.), The New institutionalism in organizational analysis: vii, 478 p. Chicago: University of Chicago Press.

Gereffi, G. \& Kaplinsky, R. 2001. The Value of Value Chains: Spreading the Gains from Globalization. IDS Bulletin, 32(3).

Gereffi, G. 2003. The Governance of Global Value Chains: An Analytic Framework. Under review at Review of International Political Economy.

Goelman, A. \& Massachusetts Institute of Technology. Dept. of Urban Studies and Planning. 2005. $\underline{A}$ spatial structuring approach to IT use and workplace change : what's space got to do with it? Unpublished Thesis Ph. D. --Massachusetts Institute of Technology Dept. of Urban Studies and Planning 2005.

Grumbach, K. 2002. Fighting hand to hand over physician workforce policy: the invisible hand of the market meets the heavy hand of government planning. Health Affairs, 21(5): 13-27.

Hall, P. A. \& Soskice, D. W. 2001. Varieties of capitalism : the institutional foundations of comparative advantage. Oxford [England] ; New York: Oxford University Press.

Harrison, S. 1992. Just managing : power and culture in the National Health Service. Houndmills, Basingstoke, Hampshire: Macmillan. 
Hay, C. \& Rosamond, B. 2002. Globalization, European integration and the discursive construction of economic imperatives. Journal of European Public Policy, 9(2): 147-167.

Immergut, E. M. 1992. Health politics : interests and institutions in Western Europe. Cambridge [England] ; New York, NY, USA: Cambridge University Press.

Kalyanpur, A., Weinberg, J., \& Nklesa, V. 2003. Emergency Radiology coverage: technical and clinical feasibility of an international teleradiology model. Emergency Radiology, 10(115-118).

Khalik, S. 2005. Outsource routine X-ray work; It can save time and costs, and let radiologists focus on high-end work, The Straits Times (Singapore): September 8, 2005.

Khalik, S. 2006. More medical degrees recognised here; 29 universities to be added to the list by April to ease future doctor shortage, The Straits Times (Singapore): March 27, 2006.

Klein, R. 1998. Why Britain is reorganizing its national health service - Yet again. Health Affairs, 17(4): 111-125.

Lawrence, T. B. 1999. Institutional Strategy. Journal of Management, 25(2): 161-188.

Lawrence, T. B. \& Suddaby, R. 2006. Institutions and Institutional Work. In S. Clegg \& C. Hardy \& W. R. Nord (Eds.), The Sage handbook of organization studies, 2nd ed.: xxii, 895 p. London ; Thousand Oaks, Calif.: Sage Publications.

Le Grand, J. 1999. Competition, cooperation, or control? Tales from the British National Health Service. Health Affairs, 18(3): 27-39.

Lee, K. Y. 2006. Prescription for a robust health sector, The Straits Times (Singapore): April 17, 2006.

Leonhardt, D. 2006. Political Clout In the Age Of Outsourcing, The New York Times, April 19, 2006 ed.: C1.

Levy, F. \& Murnane, R. J. 2004. The new division of labor : how computers are creating the next job market. New York, Princeton, N.J.: Russell Sage Foundation ;Princeton University Press.

Levy, F., Goelman, A., \& Yu, K.-H. 2006. Paging Dr. Gupta: The barriers to reading MRIs long distance. Milken Institute Review(June 2006).

Linton, O. W. 2001. Radiology at Massachusetts General Hospital: 1896-2000: General Hospital Corporation.

Margulis, A. R. \& Sunshine, J. H. 2000. Radiology at the turn of the millennium. Radiology, 214(1): 1523.

Mintzberg, H. 1979. The structuring of organizations : a synthesis of the research. Englewood Cliffs, N.J.: Prentice-Hall.

Mintzberg, H. \& Quinn, J. B. 1991. The strategy process : concepts, contexts, cases (2nd ed.). Englewood Cliffs, N.J.: Prentice Hall.

O'Malley, A. S. \& Reschovsky, J. D. 2006. No Exodus: Physicians and Managed Care Networks, Tracking Report, Vol. 14: Center for Studying Health System Change.

Peckham, S. E. M. 2003. Primary care in the UK : policy, organisation and management. Houndmills, Basingstoke, Hampshire: New York.

Pollack, A. 2003. Who's Reading Your X-ray?, The New York Times: November 16, 2003.

Reinhardt, U. 1999. The predictable managed care kvetch on the rocky road from adolescence to adulthood. Journal of Health Politics, Policy and Law, 24(5): 897-911. 
Scott, W. R. 2001. Institutions and organizations (2nd ed.). Thousand Oaks, Calif.: Sage Publications.

Scott, W. R. 2004. Competing Logics in Healthcare: Professional, State and Managerial. In F. Dobbin (Ed.), The sociology of the economy: viii, 343 p. New York: Russell Sage Foundation.

Srinivas, S. 2004. Technological learning and the evolution of the Indian pharmaceutical and biopharmaceutical sectors. Unpublished Thesis Ph. D. --Massachusetts Institute of Technology Dept. of Urban Studies and Planning 2004.

Streeck, W. \& Thelen, K. 2005. Introduction: Institutional Change in Advanced Political Economies. In W. Streeck \& K. A. Thelen (Eds.), Beyond continuity : institutional change in advanced political economies: xviii, 290 p. Oxford ; New York: Oxford University Press.

Sturgeon, T. J. \& Lester, R. K. 2002. Upgrading East Asian Industries: New Challenges for Local Suppliers. Cambridge, MA: Industrial Performance Center, Massachusetts Institute of Technology.

Suddaby, R. \& Greenwood, R. 2005. Rhetorical strategies of legitimacy. Administrative Science Quarterly, 50(1): 35-67.

Sunshine, J. H., Bansal, S., \& Evens, R. G. 1993. Radiology Performed by Nonradiologists in the United States: Who Does What? American Journal of Roentgenology, 161: 419-429.

Sunshine, J. H. \& Evens, R. G. 1994. The Challenge of Managed Care and Managed Competition. American Journal of Roentgenology, 162(4): 767-771.

Velloor, R. 2005. Now, even medical scans get outsourced, The Straits Times (Singapore): September 29, 2005.

Wiley, G. 2005. Teleradiology 2005: Cracks in the nighthawk egg. Decisions in Imaging Economics, February, 2005. 